\title{
Enzymatic RNA production from NTPs synthesized from nucleosides and trimetaphosphate
}

\author{
Fabio Chizzolini, ${ }^{\ddagger 1}$ Alexandra D. Kent, ${ }^{\ddagger 2}$ Luiz F. M. Passalacqua,${ }^{\ddagger 1}$ and Andrej Lupták ${ }^{* 1-3}$ \\ 1. Department of Pharmaceutical Sciences, University of California at Irvine, Irvine, CA 92617 \\ 2. Department of Chemistry, University of California at Irvine, Irvine, CA 92617 \\ 3. Department of Molecular Biology and Biochemistry, University of California at Irvine, Irvine, CA \\ 92617 \\ * Andrej Lupták \\ aluptak@uci.edu \\ ${ }^{\ddagger}$ These authors contributed equally \\ Supporting information is given at the end of the document.
}

\begin{abstract}
A mechanism of nucleoside triphosphorylation would have been critical in an evolving "RNA world" to provide high-energy substrates for reactions such as RNA polymerization. However, synthetic approaches to produce ribonucleoside triphosphoates (rNTPs) have suffered from conditions such as high temperatures or high $\mathrm{pH}$ that lead to increased RNA degradation, as well as substrate production that cannot sustain replication. We demonstrate that cyclic trimetaphosphate (cTmp) can react with nucleosides to form rNTPs under mild, prebiotically-relevant conditions, with second-order rate constants ranging from $1.7 \times 10^{-6}$ to $6.5 \times 10^{-6} \mathrm{M}^{-1} \mathrm{~s}^{-1}$. The ATP reaction shows a linear dependence on $\mathrm{pH}$ and $\mathrm{Mg}^{2+}$, and an enthalpy of activation of $88 \pm 4 \mathrm{~kJ} / \mathrm{mol}$. At millimolar nucleoside and cTmp concentrations, the rNTP production rate is sufficient to facilitate RNA synthesis by both T7 RNA polymerase and a polymerase ribozyme. We suggest that the optimized reaction of cTmp with nucleosides may provide a viable connection between prebiotic nucleotide synthesis and RNA replication.
\end{abstract}

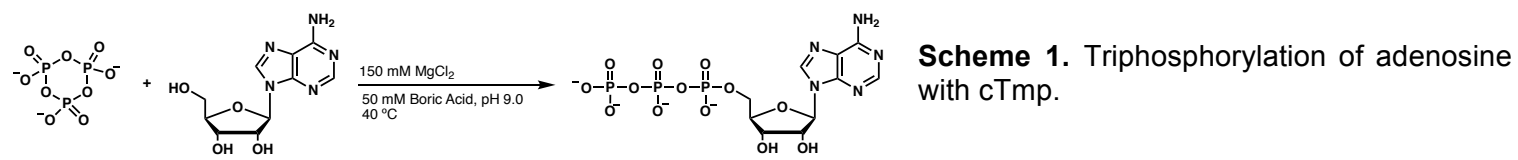

Efforts to elucidate the chemical processes by which life arose on Earth suggest that ribonucleic acid (RNA) was the first biopolymer capable of sustaining Darwinian evolution. ${ }^{[1-7]}$ In order to establish a plausible path to an RNA-only system, it is critical to connect prebiotic formation of nucleosides and ribozyme evolution through development of reactions that yield activated substrates, particularly nucleoside triphosphates (rNTPs). ${ }^{[8-15]}$ Cyclic trimetaphosphate (cTmp) has been shown to be particularly promising as both a prebiotically-relevant and a highly reactive substrate among polyphosphorylating reagents. ${ }^{[16-19]}$ Several reports have demonstrated that cTmp is capable of phosphorylating a number of different substrates, including nucleosides. ${ }^{[20-27]}$ However, these reactions typically require conditions that are not generally favorable for RNA stability, such as high $\mathrm{pH}$, additional cofactors, high temperatures, and urea. ${ }^{[28-30]}$ We address these limitations by optimization of a cTmp reaction to produce the canonical $5^{\prime}$-triphosphorylated ribonucleosides in sufficient concentrations to synthesize RNA by both protein and ribozyme RNA polymerases.

In order to measure the low concentrations of nucleoside triphosphates, we developed an ultrasensitive ATP detection assay using highly purified firefly luciferase (Fluc) ${ }^{[31]}$ and a cooled EM-CCD detector equipped with a high-numerical aperture (NA 0.6) lens system, allowing the detection of ATP down to pM concentrations and monitoring of multiple reactions in parallel. We confirmed previous experiments showing that the reaction between adenosine and cTmp is likely base-catalyzed (Figure 1A). ${ }^{[32]}$ The reaction was independent of the buffer identity (Figure 1A-C and Figure S1-S2), and the rate constants exhibited different slopes below and above neutral $\mathrm{pH}$, suggesting that the rate-limiting step is different in these two regimes. We also observed that the reaction dependence on $\mathrm{Mg}^{2+}$ ions increases linearly up to $\sim 200 \mathrm{mM}$ with a slope of $\sim 1.1$; consistent with a $\mathrm{Mg}^{2+}$-catalyzed rate-limiting step (Figure 1B). Given the relatively high concentration at which the $\mathrm{Mg}^{2+}$ curve reaches saturation, this rate-limiting step likely does not involve $\mathrm{Mg}^{2+}$ coordination by multiple phosphates of the cTMP; rather, a weakly coordinating position, such as the $5^{\prime}$ oxyanion, that likely acts as the nucleophile in the triphosphorylation reaction. ${ }^{[3,34]}$ We also measured the enthalpy and entropy of activation of ATP production from nucleosides and cTmp. An Eyring plot (Figure 1C) revealed the enthalpy of activation of $88 \pm 4 \mathrm{~kJ} / \mathrm{mol}$ and entropy of $-66 \pm 10$ $\mathrm{J} / \mathrm{mol} \cdot \mathrm{K}$. This relatively high energetic barrier highlights the importance of a catalyzed ATP synthesis for early selfreplicating systems to emerge.

To detect the formation of other nucleoside triphosphates (NTPs) with firefly luciferase, we developed a coupled enzymatic assay using nucleoside $5^{\prime}$-diphosphate kinase, which transfers the gamma phosphate of nucleoside triphosphates to ADP, yielding a molecule of ATP for each NTP. ${ }^{[35]}$ Triphosphorylation was confirmed 
for all four RNA nucleotides, with rate constants estimated to be $4.8 \times 10^{-6} \mathrm{M}^{-1} \mathrm{~s}^{-1}$ for ATP, $1.7 \times 10^{-6} \mathrm{M}^{-1} \mathrm{~s}^{-1}$ for GTP, $3.5 \times 10^{-6} \mathrm{M}^{-1} \mathrm{~s}^{-1}$ for CTP, and $6.5 \times 10^{-6} \mathrm{M}^{-1} \mathrm{~s}^{-1}$ for UTP (Figure 1D and S3). We further confirmed the synthesis of the nucleotides using anion-exchange liquid chromatography and assigned the phosphorylation states of the peaks in the chromatogram by co-injecting known amounts of AMP, ADP, and ATP (Figure 1E) or one of the other three rNTPs, as appropriate (Figure 1F). The guanosine reaction suffered both from lower levels of GTP production and from the generation of additional side products. This result corroborates the luciferase assay, which indicated that GTP synthesis is more challenging than synthesis of the other canonical rNTPs (Figure 1D).

A

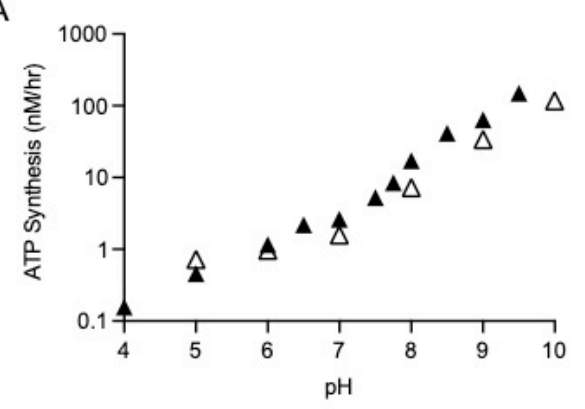

B

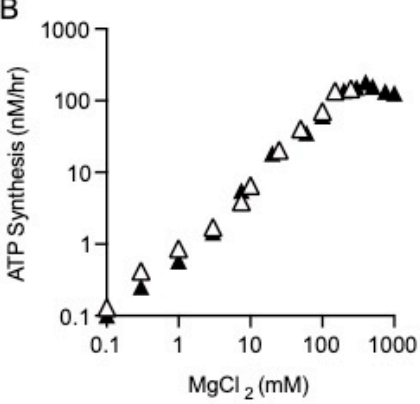

C

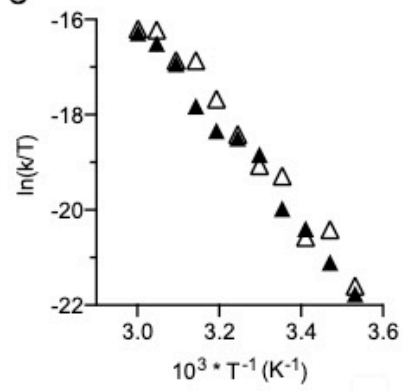

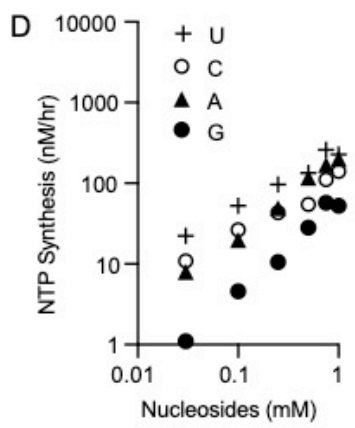
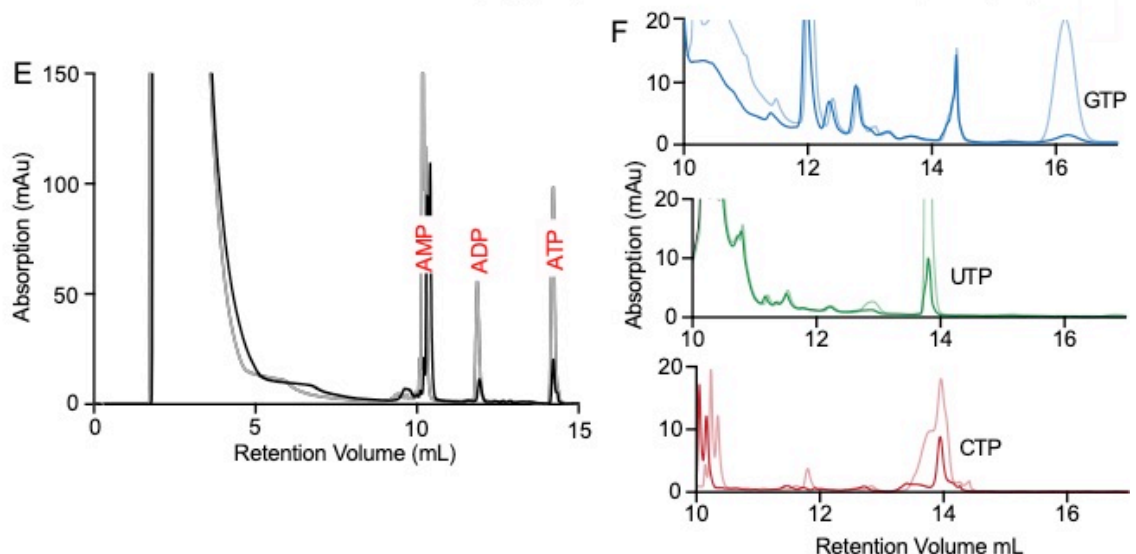

Figure 1. Reaction analysis of nucleoside triphosphorylation by trimetaphosphate. ATP synthesis rate measured as a function of $\mathrm{pH}(\mathrm{a})$ and $\mathrm{Mg}^{2+}$ ions (b) in a three-buffer system (white) or a boric acid system (black), measured using a firefly luciferase assay. (c) An Eyring plot for the reaction, revealing the activation enthalpy as $88 \pm 4$ $\mathrm{kJ} / \mathrm{mol}(20.9 \pm 1.1 \mathrm{kcal} / \mathrm{mol})$ for boric acid (black), and $87 \pm 3 \mathrm{~kJ} / \mathrm{mol}(20.8 \pm 0.7 \mathrm{kcal} / \mathrm{mol})$ for the three-buffer system (white). The entropy was calculated as $-66 \pm 10 \mathrm{~J} / \mathrm{mol} \cdot \mathrm{K}$ and $-70 \pm 9 \mathrm{~J} / \mathrm{mol} \cdot \mathrm{K}$ (white), respectively. (d) Synthesis of all four canonical ribonucleotide triphosphates measured using a firefly luciferase assay coupled to $5^{\prime}$ diphosphate kinase, which uses rNTPs to produce ATP. (e) Anion exchange chromatography showing production of ATP. The trace of the reaction products (black line) was overlaid with a chromatographic trace of the same reaction supplemented with $2 \mu \mathrm{M}$ of AMP, ADP, and ATP (gray line) to confirm the phosphorylation state of the products. (f) Anion exchange chromatography showing production of other rNTPs (dark line) overlaid with $2 \mu \mathrm{M}$ of each rNTP standard (light line).

To demonstrate the utility of this reaction, we used the synthesized nucleotides to sustain RNA transcription using T7 RNA polymerase. We chose to transcribe an HDV-like ribozyme, drz-Fpra-2, because of its small size and because its self-scission requires high-fidelity transcription. ${ }^{[36]} \mathrm{A}$ band corresponding to the full-size transcript of drz-Fpra-2 was readily observed when using only the cTmp-derived nucleotides (Figure 2A). However, no cleavage product was detected, likely due to substitution of guanosine with other nucleotides. To test this model, we supplemented the transcription with GTP and observed a greatly increased yield of the transcripts and the fraction of active ribozymes (Figure 2B). Similarly, we used the synthesized nucleotides with tC19Z, a polymerase ribozyme capable of extending an RNA primer along an RNA template. ${ }^{[11]}$ PAGE analysis showed the addition of three of the four nucleotides (Figure 2C and Figure S4), with the polymerase activity apparently again limited by the low concentration of GTP. 
A

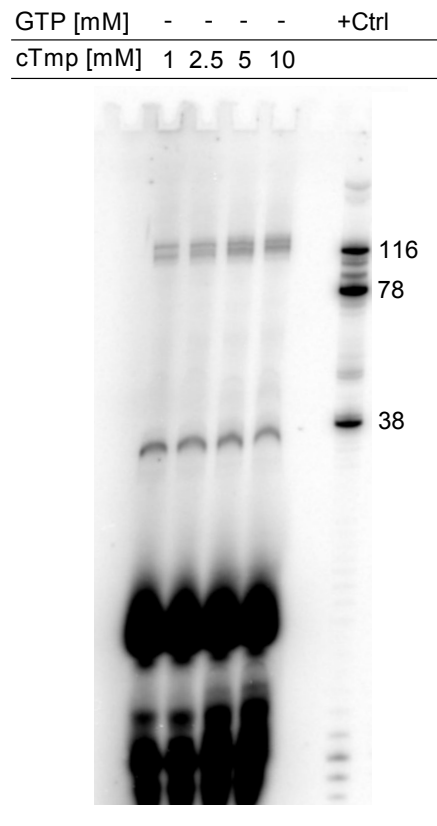

B

$0.10 .250 .512+$ Ctrls

$\begin{array}{llllllll}5 & 5 & 5 & 5 & 5 & 5 & 5 & 5\end{array}$

C

\begin{tabular}{|c|c|c|c|c|c|c|}
\hline+ & + & + & - & - & + & tC19Z \\
\hline+ & + & + & + & - & - & rNTPs \\
\hline+ & + & - & - & + & + & cTmp rxn \\
\hline
\end{tabular}

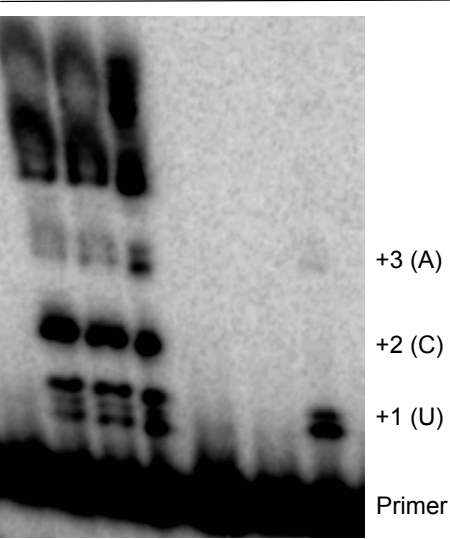

Figure 2. In vitro RNA production coupled to cTmp-derived rNTPs. (a) In vitro transcriptions of a self-cleaving ribozyme. cTmp reactions were diluted into T7 RNA polymerase reactions to produce the drz-Fprau-2 self-cleaving ribozyme. A control reaction (+Ctrl) with additional rNTPs shows production of full-length ribozyme, as well as the products of self-scission. (b) Transcription reactions with cTmp-derived NTPs supplemented with GTP at concentrations indicated above the gel, showing robust transcription initiation and production of active ribozymes. Control reactions (+Ctrls) include a five-fold serial dilution series of transcriptions containing all NTPs. (c) A laboratory-evolved polymerase ribozyme, tC19Z, utilizing cTmp-derived rNTPs to extend a primer along a template. Lanes 1-3 (left to right) show positive controls and lanes 4-5 negative control reactions. Lane 6 resolves the reaction containing cTmp-generated nucleotides and shows extension of three nucleotides along the template.

In summary, we synthesized all four canonical nucleoside triphosphates from cTmp and nucleosides, and utilized them in RNA synthesis. We found that in each NTP synthesis reaction, the formation of GTP was significantly lower than formation of the other three nucleosides. We hypothesize that reduced GTP synthesis may result from relatively low solubility and the propensity for guanosine to assume the anti conformation in solution, perhaps hindering the $5^{\prime}$ oxygen from reacting with cTmp. This was further corroborated by the presence of additional peaks in the chromatograms of the guanosine-cTmp reaction, which likely represent other phosphoguanosines (Figure 1F). The low concentrations of GTP present in the reactions presented a unique challenge when transcribing and copying RNA. Although RNA was successfully produced and detected in each case, yields were low or GTP was not incorporated in appreciable amounts, as was the case in ribozyme-mediated primer-extension. Thus, robust RNA production may require an alternate route to GTP synthesis or reliance on ribozymes that are composed of only two or three types of nucleotides. ${ }^{[37,38]}$ Nevertheless, rNTP synthesis in prebiotically-relevant conditions provides a crucial link between nucleoside formation and RNA production. Further development of this reaction with alternative conditions to increase GTP synthesis or by the introduction of ribozymes that enhance the rate of production would have been crucial for an evolving system to emerge. ${ }^{[39,40]}$ 


\section{Acknowledgements}

This work was supported by grants from the John Templeton Foundation through the Foundation for Applied Molecular Evolution and NSF-CBET 1804220 and NASA 20-EXO20-0110 (A.L.), NSF Graduate Research Fellowship (A.D.K.), and Science Without Borders Program, CAPES Foundation, Ministry of Education of Brazil, Process 99999.013571/2013-03, and Miguel Velez Scholarship-UCI (L.P.).

\section{References}

[1] M. Neveu, H. J. Kim, S. A. Benner, Astrobiology 2013, 13, 391-403.

[2] M. P. Robertson, G. F. Joyce, Cold Spring Harb. Perspect. Biol. 2012, 4, a003608.

[3] J. P. Schrum, T. F. Zhu, J. W. Szostak, Cold Spring Harb. Perspect. Biol. 2010 , 2, a002212.

[4] D. P. Bartel, P. J. Unrau, Trends Cell Biol. 1999, 9, 9-13.

[5] N. Lehman, in W. J. Lennarz, M.D.B.T.E. of B.C. (Second Ed.), Academic Press, Waltham, 2013, pp. $142-146$.

[6] X. Chen, N. Li, A. D. Ellington, Chem. Biodivers. 2007, 4, 633-655.

[7] L. L. Martin, P. J. Unrau, U. F. Müller, Life 2015, 5, 247-268.

[8] J. D. Sutherland, Angew. Chemie Int. Ed. 2016, 55, 104-121.

[9] J. D. Sutherland, Cold Spring Harb. Perspect. Biol. 2010, 2, a005439-a005439.

[10] J. D. Sutherland, J. N. Whitfield, Tetrahedron Lett. 1997, 38, 1451-1454.

[11] A. Wochner, J. Attwater, A. Coulson, P. Holliger, Science 2011, 332, 209-212.

[12] E. H. Ekland, J. W. Szostak, D. P. Bartel, Science 1995, 269, 364-370.

[13] D. P. Horning, G. F. Joyce, Proc. Natl. Acad. Sci. 2016, 113, 9786-9791.

[14] R. Lohrmann, L. E. Orgel, Nature 1973, 244, 418-420.

[15] M. A. Pasek, M. Gull, B. Herschy, Chem. Geol. 2017, 475, 149-170.

[16] M. A. Pasek, J. P. Harnmeijer, R. Buick, M. Gull, Z. Atlas, Proc. Natl. Acad. Sci. 2013, 110, 10089-10094.

[17] M. A. Pasek, Proc. Natl. Acad. Sci. 2008, 105, 853-858.

[18] R. Osterberg, L. E. Orgel, J. Mol. Evol. 1972, 1, 241-248.

[19] M. Tsuhako, M. Fujimoto, S. Ohashi, H. Nariai, I. Motooka, Bull. Chem. Soc. Jpn. 1984, 57, 3274-3280.

[20] S. Mohamady, S. D. Taylor, Org. Lett. 2013, 15, 2612-2615.

[21] S. Mohamady, S. D. Taylor, Org. Lett. 2016, 18, 580-583.

[22] S. M. Shepard, C. C. Cummins, J. Am. Chem. Soc. 2019, 141, 1852-1856.

[23] I. Sibilska, Y. Feng, L. Li, J. Yin, Orig. Life Evol. Biosph. 2018, 48, 277-287.

[24] A. W. Schwartz, J. Chem. Soc. D Chem. Commun. 1969, 1393a-1393a.

[25] R. Saffhill, J. Org. Chem. 1970, 35, 2881-2883.

[26] C. Cheng, C. Fan, R. Wan, C. Tong, Z. Miao, J. Chen, Y. Zhao, Orig. life Evol. Biosph. 2002, 32, $219-224$.

[27] H. J. Kim, S. A. Benner, Astrobiology 2021, DOI 10.1089/ast.2020.2264.

[28] G. A. Soukup, R. R. Breaker, RNA 1999, 5, 1308-1325.

[29] Y. Li, R. R. Breaker, J. Am. Chem. Soc. 1999, 121, 5364-5372.

[30] M. Levy, S. L. Miller, Proc. Natl. Acad. Sci. 1998, 95, 7933-7938.

[31] L. C. Tisi, P. J. White, D. J. Squirrell, M. J. Murphy, C. R. Lowe, J. A. H. Murray, Anal. Chim. Acta 2002, 457, 115-123.

[32] E. Etiax, L. E. Orgel, J. Carbohydrates Nucleosides Nucleotides 1978, 5, 91-110.

[33] H. W. Jones, C. B. Monk, C. W. Davies, J. Chem. Soc. 1949, 2693-2695.

[34] Y. Yamagata, H. Inoue, K. Inomata, Orig. Life Evol. Biosph. 1995, 25, 47-52.

[35] I. Lascu, P. Gonin, J. Bioenerg. Biomembr. 2000, 32, 237-246.

[36] L. F. M. Passalacqua, R. M. Jimenez, J. Y. Fong, A. Lupták, Biochemistry 2017, 56, 6006-6014.

[37] J. Rogers, G. F. Joyce, Nature 1999, 402, 323-325.

[38] J. S. Reader, G. F. Joyce, Nature 2002, 420, 841-844.

[39] J. E. Moretti, U. F. Müller, Nucleic Acids Res. 2014, 42, 4767-4778.

[40] G. F. Dolan, A. Akoopie, U. F. Müller, PLoS One 2015, 10, e0142559. 
Enzymatic RNA production from NTPs synthesized from nucleosides and trimetaphosphate

Fabio Chizzolini ${ }^{\ddagger 1}$, Alexandra D. Kent ${ }^{\ddagger 2}$, Luiz F. M. Passalacqua ${ }^{\ddagger 1}$, and Andrej Lupták ${ }^{1-3}$

1. Department of Pharmaceutical Sciences, University of California at Irvine, Irvine, CA 92617

2. Department of Chemistry, University of California at Irvine, Irvine, CA 92617

3. Department of Molecular Biology and Biochemistry, University of California at Irvine, Irvine, CA 92617

\section{Table of Contents}

Materials and Methods

S1. ATP synthesis is independent of boric acid

S2. Temperature dependence of ATP synthesis is independent of buffer identity

S3. ATP synthesis as a function of adenosine or cTmp

S4. RNA extension by an RNA polymerase using synthesized nucleotides

Table S1. Sequences

References 
Materials and Methods.

All chemicals were purchased from Sigma-Aldrich, unless otherwise stated.

ATP detection by chemo-luminescent assay.

ATP was detected using the highly thermostable StayBrite luciferase enzyme (BioVision). In order to remove trace amounts of ATP present in the enzyme stock, StayBrite luciferase was pre-incubated for 6 hours at room temperature in a solution containing $3 \mu \mathrm{M}$ luciferase enzyme, $50 \mu \mathrm{M}$ D-luciferin, $200 \mu \mathrm{M}$ ammonium sulfate, $1 \mathrm{mM}$ dithiothreitol (DTT), $20 \mathrm{mM} \mathrm{MgCl}_{2}$, and $25 \mathrm{mM}$ Tris- $\mathrm{HCl}$ at $\mathrm{pH}$ 7.4. After this pre-incubation, ATP was detectable down to $10 \mathrm{pM}$ concentration. ATP detection was performed by mixing 2 parts of pre-incubated enzyme solution with 1 part of the ATP-containing solution on a glass coverslip (Fisher Scientific) attached to a Frame-Seal chamber (Bio-Rad). The chamber was then closed by a second glass coverslip. The closed Frame-Seal chamber was then attached to a mirror and mounted in front of a macro lens system constructed by mounting two Nikkor $\mathrm{f} / 1.2$ lenses in opposition. The macro lens system images an area of the same size as the CCD chip on the camera. In our case, this system images an area approximately the size of the Frame-Seal chamber, ensuring that most of the luminescence output is directed to the chip of an EMCCD camera (iXon Ultra 888, Andor). The temperature of chip of the EMCCD camera was maintained at $-100{ }^{\circ} \mathrm{C}$ during detection using a thermoelectric recirculating chiller (Thermocube 300, Solid State Cooling Systems). The sample slides were held on the mirror using a paper clip and mounted on a micrometer connected to a sliding platform for the precise focusing. To prevent contamination from environmental light sources, the sample was isolated with two nested dark boxes (Thorlabs) and kept in a dark room. Standard curves were generated using increasing concentrations of ATP in order to convert the luminescence output of samples containing unknown amounts of ATP to molar concentration.

CTP, GTP, and UTP detection by enzymatic phosphorylation of ADP to ATP.

In order to detect CTP, GTP, and UTP using the ATP-dependent chemo-luminescent assay described above, the enzyme nucleoside 5'-diphosphate kinase (NDK) was used. ${ }^{1}$ The kinase used either CTP, GTP, or UTP as the substrate to phosphorylate ADP to ATP. Samples containing the triphosphorylated nucleotides to be used as substrates for the ATP production were diluted 10-fold in $10 \mathrm{mM}$ 2-amino-2-(hydroxymethyl)propane-1,3-diol (Tris), $0.1 \mathrm{mM}$ EDTA at pH 7.4 (buffer TE), along with 0.05 units of the kinase enzyme and $50 \mathrm{nM}$ ADP. The ADP used was purified using ion-exchange chromatography to remove trace amounts of ATP. The phosphorylation reaction was incubated for 5 minutes at room temperature, after which the samples were analyzed using the luciferasebased assay described above. Standard curves were generated by using the same conditions for ATP phosphorylation as for the unknown samples and by including increasing concentrations of commercial CTP, GTP, and UTP, as appropriate. The standard curves were then used to convert the luminescence output of the luciferase assay to the molar concentration of each of the individual triphosphorylated nucleotides.

Adenosine phosphorylation reaction.

Adenosine and cyclic trimetaphosphate (cTmp) were allowed to react under different conditions, and the production of ATP was assessed using the luciferase assay described above. To derive the ATP synthesis rate, ATP production was measured multiple times during the reaction. Standard conditions were $1 \mathrm{mM}$ adenosine, 10 $\mathrm{mM}$ cTmp, $150 \mathrm{mM} \mathrm{MgCl}_{2}$, and $50 \mathrm{mM}$ boric acid at $\mathrm{pH}$ 9.0. The $\mathrm{pH}$ was adjusted using sodium hydroxide after all the components of the reactions were mixed together. The standard temperature for the reaction was $40{ }^{\circ} \mathrm{C}$, unless otherwise stated. The $\mathrm{pH}$ dependence of ATP production was assessed using a three-component buffer system, in which the $\mathrm{pH}$ could be directly titrated from 4.0 to 10.0. This was done in order to maintain constant ionic strength of the solution. The system was composed of $100 \mathrm{mM}$ acetic acid, $100 \mathrm{mM} 2-(\mathrm{N}-$ morpholino)ethanesulfonic acid (MES), and $100 \mathrm{mM}$ boric acid. To assess the possible role of boric acid on the catalysis of ATP, boric acid was replaced with $N$-cyclohexyl-2-aminoethanesulfonic acid (CHES). Prior to the luciferase assay measurement of ATP concentration, the synthesis reactions were diluted 10 -fold in TE buffer.

Guanosine, cytidine, and uridine phosphorylation reactions.

Guanosine, cytidine, or uridine at a concentration of $1 \mathrm{mM}$ were allowed to react with $10 \mathrm{mM}$ cyclic trimetaphosphate (cTmp) in a buffer containing $150 \mathrm{mM} \mathrm{MgCl}_{2}$ and $50 \mathrm{mM}$ boric acid with pH adjusted to 9.0 using sodium hydroxide. Reactions were carried out at $40^{\circ} \mathrm{C}$, and aliquots were taken out at different time points in order to estimate the synthesis rates of the different triphosphorylated nucleotides. At each time point, the concentration of GTP, CTP, or UTP, respectively, was measured through the coupled enzymatic phosphorylation of ADP and chemiluminescence measurement with the luciferase assay, as described above.

FPLC analysis of phosphorylation reaction products.

An FPLC Äkta Purifier UPC-10 system (GE Healthcare) was used to analyze the products of the reactions between nucleosides and cTmp. All reactions were performed with $50 \mathrm{mM} \mathrm{cTmp}$ and $50 \mathrm{mM} \mathrm{MgCl}_{2}$ in $50 \mathrm{mM}$ boric acid $(\mathrm{pH}$ 9.0). Starting concentrations of the nucleosides for the different reactions were $25 \mathrm{mM}$ adenosine, $25 \mathrm{mM}$ guanosine, $50 \mathrm{mM}$ cytidine, and $50 \mathrm{mM}$ uridine. Reactions were incubated at $40{ }^{\circ} \mathrm{C}$ for 4 hours, and afterwards diluted 20 -fold in TE buffer. Approximately $1 \mathrm{~mL}$ of the diluted reactions was then loaded onto the FPLC system, and the reaction products were separated by charge using a DNAPac PA-100 column (Dionex) with a linear gradient of $0.9 \mathrm{M}$ ammonium carbonate. Control reactions were performed using the same compositions 
supplemented with $2 \mu \mathrm{M}$ of either ATP, GTP, CTP, or UTP, as appropriate. In the case of the ATP synthesis reaction, $2 \mu \mathrm{M}$ of ADP and $2 \mu \mathrm{M}$ of AMP were co-injected with the ATP standard.

RNA synthesis from triphosphorylated nucleosides with T7 RNA polymerase.

A triphosphorylation reaction to synthetize the four rNTPS starting from the four nucleosides and cTmp contained $25 \mathrm{mM}$ adenosine, $25 \mathrm{mM}$ guanosine, $50 \mathrm{mM}$ uridine, $50 \mathrm{mM}$ cytidine, $10 \mathrm{mM} \mathrm{cTmp}, 50 \mathrm{mM} \mathrm{MgCl}_{2}$, and $25 \mathrm{mM}$ Tris- $\mathrm{HCl}$ at $\mathrm{pH}$ 9.0. Tris- $\mathrm{HCl}$ was used as the buffer instead of boric acid, as tests showed that the presence of boric acid inhibited the activity of T7 RNA polymerase. The reaction was then incubated at $40{ }^{\circ} \mathrm{C}$ for 4 hours. An HDV-like ribozyme, drz-Fpra-2 (Supplementary Table 1), ${ }^{2}$ was used as the template for the in vitro transcription. RNA was transcribed at $37^{\circ} \mathrm{C}$ for one hour in a $20 \mu \mathrm{L}$ reaction containing $40 \mathrm{mM}$ Tris- $\mathrm{HCl}(\mathrm{pH} 7.9), 10 \mathrm{mM} \mathrm{MgCl}$, $2 \mathrm{mM}$ spermidine, $1 \mathrm{mM}$ dithiothreitol, $4.5 \mu \mathrm{Ci}$ [a- ${ }^{32} \mathrm{P}$ ]ATP (Perkin Elmer), 10 units of T7 RNA polymerase (NEB), 2 pmoles of DNA template, and $4 \mu \mathrm{L}$ of the rNTP synthesis reaction. For the positive-control reaction, $100 \mu \mathrm{M}$ ATP and $1 \mathrm{mM}$ of each GTP, UTP, and CTP were used in place of the rNTPs synthesis reaction. The transcripts were resolved on a $10 \%$ polyacrylamide gel electrophoresis (PAGE) under denaturing conditions (7 M urea). The PAGE gel was dried, exposed to a phosphor image screen, and analyzed using a Typhoon phosphorimager (GE Healthcare).

RNA Primer phosphorylation.

A primer labeling reaction was prepared in a total volume of $20 \mu \mathrm{L}$ containing $20 \mu \mathrm{M}$ of RNA primer, 1x T4 Polynucleotide Kinase (PNK) ligase buffer (NEB), 1 unit of T4 PNK enzyme (NEB), and $0.5 \mu \mathrm{Ci}\left[\mathrm{\gamma}^{32} \mathrm{P}\right] \mathrm{ATP}$ (Perkin Elmer). The reaction was incubated at $37{ }^{\circ} \mathrm{C}$ for one hour. The radiolabeled RNA primer was purified by $7.5 \%$ polyacrylamide gel electrophoresis (PAGE) under denaturing conditions (7 M urea), and the resolved gel was visualized using a Typhoon phosphorimager (GE Healthcare). The band of interest was excised, eluted from the gel into $300 \mu \mathrm{L}$ of $300 \mathrm{mM} \mathrm{KCl}$, and precipitated by adding $1 \mu \mathrm{L}$ glycoblue and $700 \mu \mathrm{L}$ of $98 \%$ ethanol at $-80{ }^{\circ} \mathrm{C}$.

RNA synthesis with cTmp derived nucleotides using tC19Z RNA polymerase ribozyme.

A reaction containing $25 \mathrm{mM}$ adenosine, $25 \mathrm{mM}$ guanosine, $50 \mathrm{mM}$ uridine, $50 \mathrm{mM}$ cytidine, $10 \mathrm{mM} \mathrm{cTmp}, 25 \mathrm{mM}$ Tris $\mathrm{HCl}(\mathrm{pH} 9.0)$, and $50 \mathrm{mM} \mathrm{MgCl} 2$ was incubated at $70{ }^{\circ} \mathrm{C}$ for 1 hour. The reaction was centrifuged to remove the unreacted nucleosides from the nucleoside triphosphates remaining in solution. Polymerase reactions were prepared in $10 \mu \mathrm{L}$ volumes where $5 \mu \mathrm{L}$ were added directly from the cTmp reaction. Additionally, the reactions contained $0.5 \mu \mathrm{M}$ tc $19 \mathrm{z}$ ribozyme (Supplementary Table 1 ), ${ }^{3} 0.5 \mu \mathrm{M}$ template, and $0.5 \mu \mathrm{M}$ [ $\alpha^{32} \mathrm{P}$ ] $5^{\prime}$-end radiolabeled RNA primer (Supplementary Table 1) in $200 \mathrm{mM} \mathrm{MgCl} 2$ and $50 \mathrm{mM}$ Tris $\mathrm{HCl}(\mathrm{pH}$ 8.0). The RNA was added first and heated at $85^{\circ} \mathrm{C}$ for two minutes, then cooled to $17^{\circ} \mathrm{C}$ for 10 minutes. The remaining reagents were added and incubated at $17{ }^{\circ} \mathrm{C}$ for 5 days. The first positive control did not contain any cTmp reaction, but had 4 $\mathrm{mM}$ of each nucleotide. The second positive control resembled the first, but with addition of the cTmp reaction. Negative controls contained cTmp reaction, but were missing either the polymerase ribozyme or the template. After 5 days, reactions were quenched with $5 \mu \mathrm{L}$ of $500 \mathrm{mM}$ EDTA and $5 \mu \mathrm{L}$ of $7 \mathrm{M}$ urea loading dye, and then were resolved on a $20 \%$ PAGE under denaturing conditions ( $7 \mathrm{M}$ urea). The PAGE gel was dried and exposed to a phosphor image screen and analyzed using a Typhoon phosphorimager (GE Healthcare). 


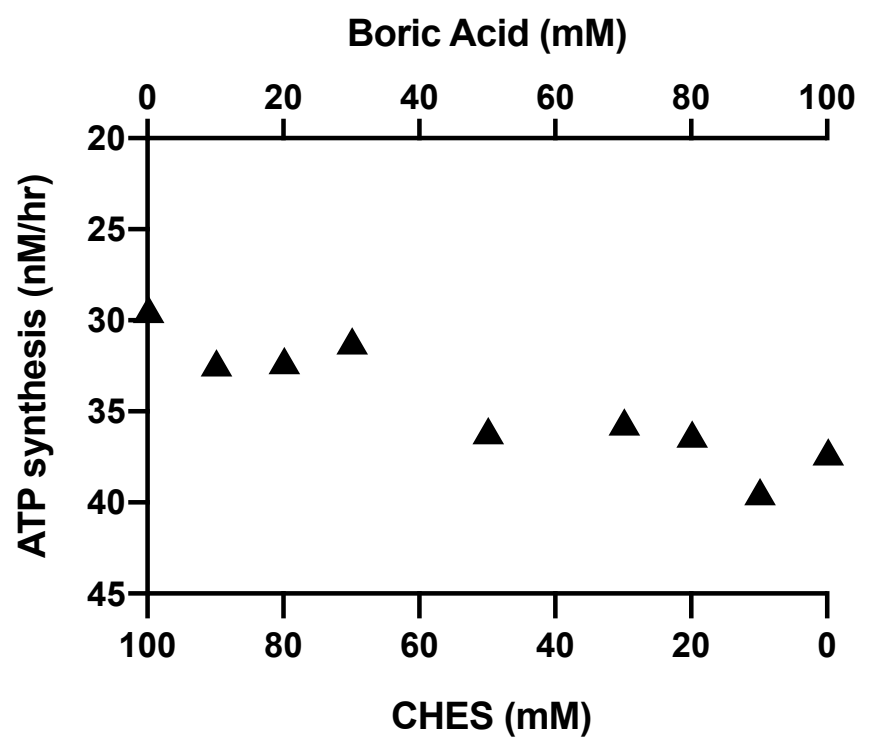

Figure S1. ATP synthesis does not depend on boric acid.

ATP synthesis rates measured in the presence of varying borate/CHES ratios. Reactions containing $1 \mathrm{mM}$ adenosine, $10 \mathrm{mM} \mathrm{cTmp}$, and $50 \mathrm{mM} \mathrm{MgCl}$ at $\mathrm{pH} 9.2$ were incubated at $40{ }^{\circ} \mathrm{C}$ in a buffer composed of $100 \mathrm{mM}$ final concentration of CHES and borate, mixed at different ratios.

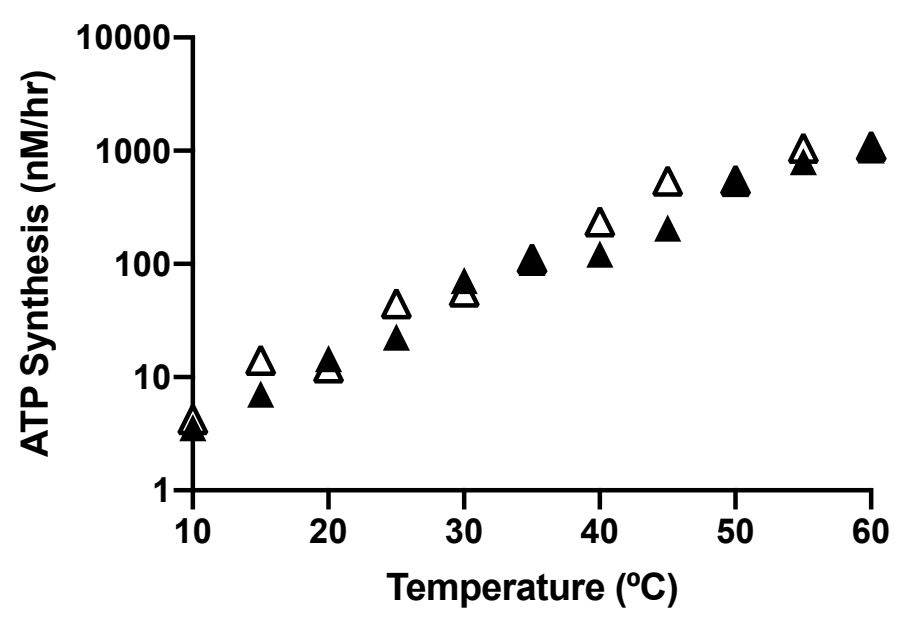

Figure S2. Temperature dependence of ATP synthesis is independent of buffer identity.

Either a three-buffer system (white), or a boric acid buffer (black), was used with a reaction consisting of $1 \mathrm{mM}$ adenosine, $10 \mathrm{mM} \mathrm{cTmp}, 150 \mathrm{mM} \mathrm{MgCl}$ at $\mathrm{pH}$ 9.0. ATP production at various temperatures was measured using the optimized luciferase assay to measure synthesis rate. 

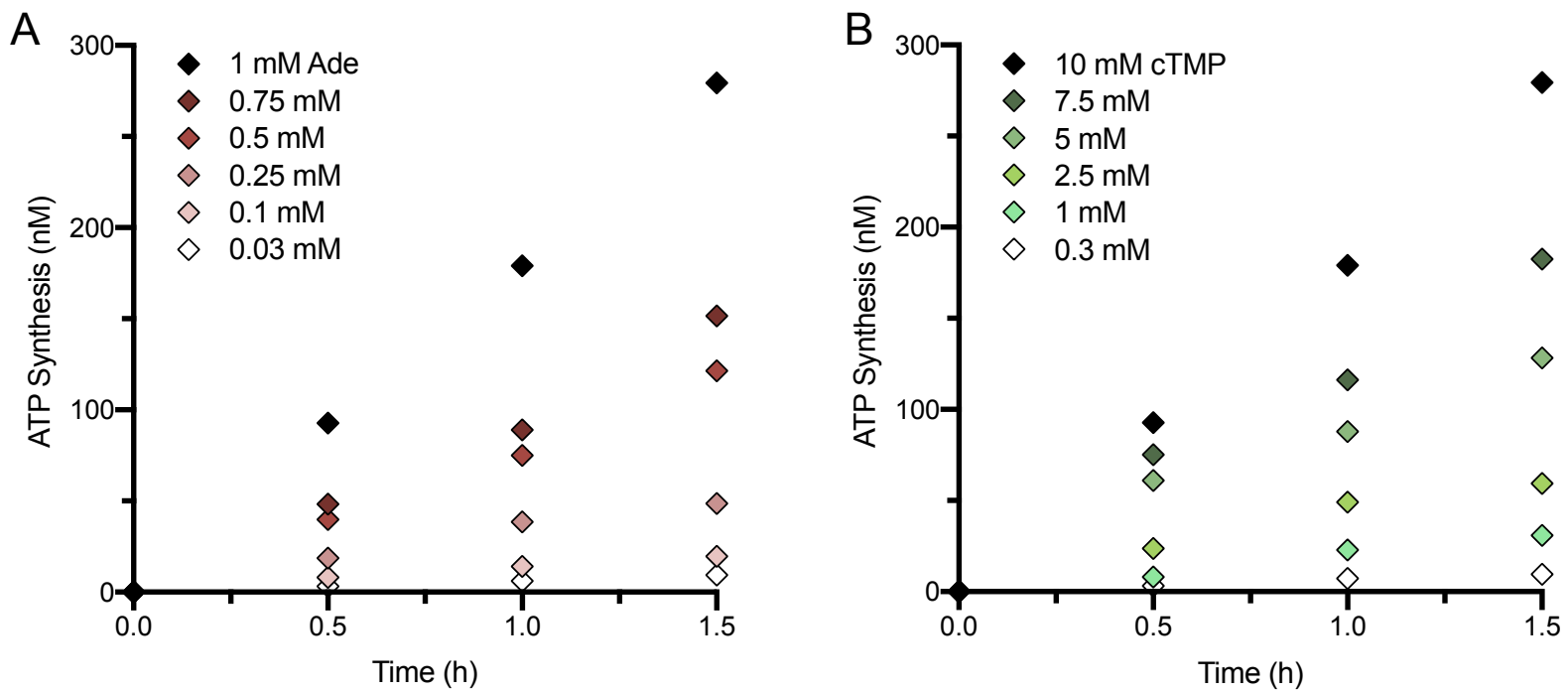

Figure S3. ATP synthesis as a function of adenosine and cTmp.

(a) Reactions containing $10 \mathrm{mM} \mathrm{cTmp}, 50 \mathrm{mM}$ boric acid, $150 \mathrm{mM} \mathrm{MgCl}_{2}$, and varying concentrations of adenosine at $\mathrm{pH} 9.0$ were allowed to react at $40{ }^{\circ} \mathrm{C}$ for up to 1.5 hours. ATP concentrations were measured using the luciferase assay. (b) $1 \mathrm{mM}$ adenosine, $50 \mathrm{mM}$ boric acid, $150 \mathrm{mM} \mathrm{MgCl}_{2}$, and varying concentrations of cTmp were allowed to react at $40{ }^{\circ} \mathrm{C}$ for up to $1.5 \mathrm{hrs}$. These data were used to calculate a second-order rate constant of approximately $4.8 \times 10^{-6} \mathrm{M}^{-1} \mathrm{~s}^{-1}$. 


\begin{tabular}{|c|c|c|c|c|c|c|c|c|c|c|c|c|}
\hline ATP [mM] & -1 & 1 & - & & - & $-\quad-$ & - & - & - & - & $-\quad-$ & \\
\hline UTP [mM] & -1 & 1 & - & & $-\quad-$ & $-\quad-$ & - & - & - & - & $-\quad-$ & 1 \\
\hline CTP [mM] & -1 & 1 & - & & - & $-\quad-$ & - & - & - & - & $-\quad-$ & 1 \\
\hline GTP [mM] & -1 & 1 & - & & $-\quad-$ & $-\quad-$ & - & - & 1 & 1 & 1 & 1 \\
\hline TMP [mM] & $-\quad-$ & 5 & 101 & & 55 & 2.52 .5 & 1 & 1 & & 5 & 1010 & 5 \\
\hline Dilution & $-\quad-$ & - & 0.40 & & 0.40 .2 & 0.40 .2 & & 0.2 & 0.40 & 0.2 & 0.40 .2 & - \\
\hline
\end{tabular}

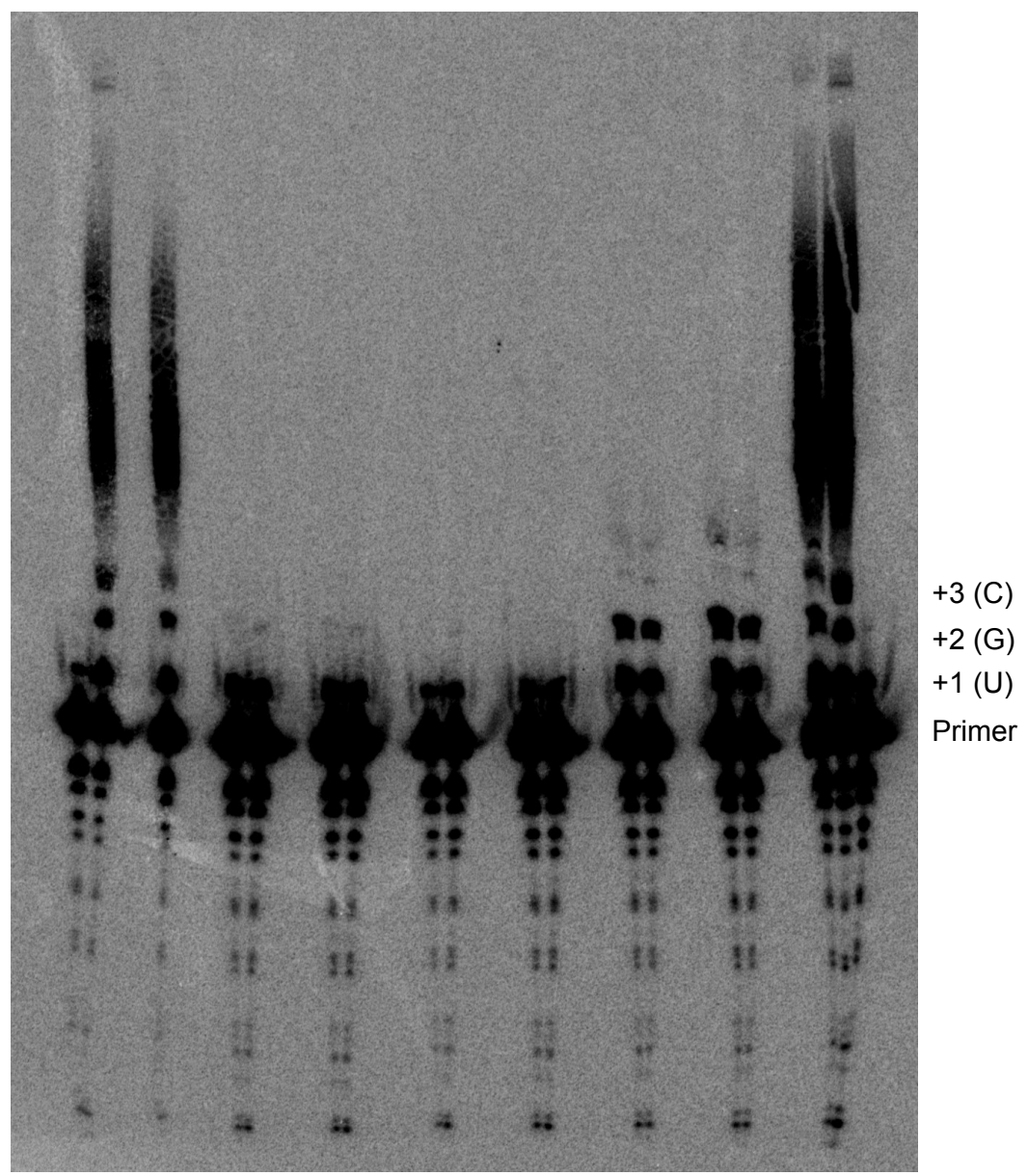

Figure S4. RNA extension by an RNA polymerase ribozyme using synthesized nucleotides.

Reactions containing $25 \mathrm{mM}$ adenosine, $25 \mathrm{mM}$ guanosine, $50 \mathrm{mM}$ uridine, $50 \mathrm{mM}$ cytidine, and indicated concentrations of cTmp in $50 \mathrm{mM} \mathrm{MgCl}$ and $25 \mathrm{mM} \mathrm{Tris-HCl}$ at pH 9.0 were incubated at $40{ }^{\circ} \mathrm{C}$ for 4 hours. The reactions were diluted either $1: 2.5$ or $1: 5$ as in RNA polymerization reactions, composed of a radiolabeled RNA primer and the RNA polymerase ribozyme (tC19Z). Some reactions were supplemented with either GTP or all four rNTPs, while a negative-control reaction contained no added nucleotides. The polymerization reactions were incubated for 36 hours at $17{ }^{\circ} \mathrm{C}$ and then resolved on a $20 \%$ polyacrylamide gel under denaturing conditions. While the no-reaction control showed a weak band corresponding to the one-nucleotide extension, the reactions using 5 $\mathrm{mM}$ and $10 \mathrm{mM} \mathrm{cTmp}$ showed extension by two nucleotides. Single nucleotide primer degradation is seen in the lower half of the gel. Consistent with what was previously observed for GTP synthesis, the reactions supplemented with GTP showed an extension of 4 nucleotides. Some reactions are shown with two different dilution factors. 
Table S1: Sequences

\begin{tabular}{|c|c|}
\hline drz-Fprau-2 Primer (Fwd.) & 5'-TTC CCG CGA AAT TAA TAC GAC TCA CTA \\
\hline drz-Fprau-2 Primer (Rev.) & 5'-GAC AAT ATT GCA TCT CAG CCA CAT \\
\hline drz-Fprau-2 DNA Full Length & $\begin{array}{l}\text { 5'-TTC CCG CGA AAT TAA TAC GAC TCA CTA TAG GGG AGA TAT AAG } \\
\text { GCT GTG GGA AGG TTC TCA CAG CTT TGC CGC TCG AAA CTT TGC ACA } \\
\text { CCT CTA CGC GGT GGG TGG CAG GCA ACA CAT GAG AAT GTG GCT } \\
\text { GAG ATG CAA TAT TGT C }\end{array}$ \\
\hline tC19Z Template Elongation (Fwd.) & $\begin{array}{l}\text { 5'-GGG AGA AGC ACA CTA AAT TGA CCT GAC GAG GCC TAA GGG GCC } \\
\text { GAA ACC GGG GCA ACC CCG }\end{array}$ \\
\hline tC19Z Template Elongation (Rev.) & $\begin{array}{l}\text { 5'-CTG CCA ACC GTC AGA AGC GTG TCA TTG ACG ACG GGG TTG CCC } \\
\text { CGG TTT CGG }\end{array}$ \\
\hline tC19Z Template Primer (Fwd.) & 5'-GCT AAT ACG ACT CAC TAT AGG GGA GAA GCA CAC TAA ATT G \\
\hline tC19Z Template Primer (Rev.) & 5'-CTG CCA ACC GTC AGA AG \\
\hline tC19Z RNA Primer & 5'-CUG CCA ACC G \\
\hline
\end{tabular}

\section{References}

1. Bergmeyer, H.-Ui. Methods Enzym. Anal. II, 488-489 (1974).

2. Passalacqua, L. F. M. et al. Biochemistry 56, 6006-6014 (2017).

3. Wochner, A. et al. Science 332, 209-212 (2011). 